\title{
Screening of breast lesions: a comparative study between mammography, B-mode ultrasonography, sonoelastography and histological results*
}

Rastreio de lesões mamárias: estudo comparativo entre a mamografia, ultrassonografia modo-B, elastografia e resultado histológico

\author{
Raquel Constantino Pardal ${ }^{1}$, António Fernando Lagem Abrantes ${ }^{2}$, Luís Pedro Vieira Ribeiro ${ }^{3}$, Rui \\ Pedro Pereira Almeida ${ }^{4}$, Kevin Barros Azevedo ${ }^{5}$, Teresa Leonor Figueiredo ${ }^{6}$, Sónia Isabel Rodrigues ${ }^{7}$
}

\begin{abstract}
Objective: To compare the capacity of mammography, sonoelastography, B-mode ultrasonography and histological analysis to differentiate benign from malignant breast lesions. Materials and Methods: A total of 12 histopathologically confirmed breast lesions were documented. The lesions were assessed by means of mammography, B-mode ultrasonography and sonoelastography, and histopathological analysis was utilized as a gold standard. Sensitivity and specificity were calculated. A receiver operating characteristic (ROC) curve was constructed to evaluate the diagnostic performance of the mentioned techniques. Results: Sensitivity and specificity in the differentiation between benign and malignant lesions were respectively $100 \%$ and $50 \%$ for mammography, $100 \%$ and $71 \%$ for B-mode ultrasonography, and $67 \%$ and $83 \%$ for sonoelastography. The area under the ROC curve was calculated for the three imaging modalities and corresponded to 0.792 for mammography, 0.847 for B-mode ultrasonography, and 0.806 for sonoelastography. Conclusion: Sonoelastography demonstrated higher specificity and lower sensitivity as compared with mammography and B-mode ultrasonography. On the other hand, B-mode ultrasonography had the largest area under the ROC curve. Sonoelastography has demonstrated to be a promising technique to detect and evaluate breast lesions, and could potentially reduce the number of unnecessary biopsies.
\end{abstract}

Keywords: Breast B-mode ultrasonography; Breast lesions; Mammography; Sensitivity; Specificity; Sonoelastography.

Resumo Objetivo: Comparar a capacidade de diferenciação de lesões benignas versus malignas por parte da mamografia, ultrassonografia modo-B e elastografia. Materiais e Métodos: Um total de 12 lesões mamárias confirmadas histologicamente foi documentado. A avaliação das lesões foi realizada por meio da mamografia, ultrassonografia modo-B e elastografia. Os resultados histopatológicos foram utilizados como técnica padrão ouro. As sensibilidades e as especificidades foram calculadas. A curva receiver operating characteristic (ROC) foi realizada para avaliar o desempenho diagnóstico das técnicas utilizadas. Resultados: A sensibilidade e a especificidade na diferenciação entre lesões mamárias benignas e malignas foram $100 \%$ e 50\%, respectivamente, para a mamografia, e $100 \%$ e $71 \%$ para a ultrassonografia modo-B. A elastografia obteve sensibilidade de $67 \%$ e especificidade de $83 \%$. A área abaixo da curva ROC foi calculada para as três técnicas imaginológicas, sendo 0,792 para a mamografia, 0,847 para a ultrassonografia modo-B e 0,806 para a elastografia. Conclusão: A elastografia mostrou ter maior especificidade e menor sensibilidade comparativamente à mamografia e à ultrassonografia modo-B. A ultrassonografia modo-B foi a técnica que demonstrou maior área abaixo da curva ROC. A elastografia mostra-se uma técnica promissora na detecção de doença mamária e, potencialmente, poderá reduzir biópsias desnecessárias.

Unitermos: Elastografia; Especificidade; Lesões mamárias; Mamografia; Sensibilidade; US modo-B mamária.

Pardal RC, Abrantes AFL, Ribeiro LPV, Almeida RPP, Azevedo KB, Figueiredo TL, Rodrigues SI. Screening of breast lesions: a comparative study between mammography, B-mode ultrasonography, sonoelastography and histological results. Radiol Bras. 2013 Jul/Ago;46(4):214220.

* Study developed at Escola Superior de Saúde da Universidade do Algarve (ESSUAlg), Algarve, Portugal.

1. Licenciate, Collaborator at Department of Radiology, Escola Superior de Saúde da Universidade do Algarve (ESSUAlg) Algarve, Portugal.

2. PhD, Member of Centro de Investigação Cesnova - Universidade Nova de Lisboa, Professor and Member of Centro de Estudos em Saúde (CES) - Escola Superior de Saúde da Universidade do Algarve (ESSUAlg), Algarve, Portugal.

3. PhD, Member of Centro de Investigação do Desporto e da Actividade Física (CIDAF) - Universidade de Coimbra, Professor and Member of Centro de Estudos em Saúde (CES) - Es- cola Superior de Saúde da Universidade do Algarve (ESSUAlg), Algarve, Portugal.

4. Postgraduate degree, Member of Centro de Estudos em Saúde (CES), Professor, Department of Radiology, Escola Superior de Saúde da Universidade do Algarve (ESSUAlg), Algarve, Portugal.

5. Licenciate, Member of Centro de Estudos em Saúde (CES), Professor, Department of Radiology, Escola Superior de Saúde da Universidade do Algarve (ESSUAlg), Algarve, Portugal.

6. Master, MD, Radiologist, Professor of the Integrated Master Degree Programme of Medical and Biomedical Sciences, Universidade do Algarve (DCBM-UAlg), Algarve, Portugal.
7. Master, Radiology Technician at Hospital de Faro, Professor, Department of Radiology, Member of Centro de Estudos em Saúde (CES) - Escola Superior de Saúde da Universidade do Algarve (ESSUAlg), Algarve, Portugal.

Mailing Address: Raquel Pardal. Departamento de Radiologia da Escola Superior de Saúde da Universidade do Algarve. Avenida Doutor Adelino da Palma Carlos, 8000-510. Faro, Portugal. E-mail: kel_pardal@hotmail.com.

Received October 18, 2012. Accepted after revision April 5, 2013. 


\section{INTRODUCTION}

Breast cancer is the most common neoplasm in the female population, comprising about $16 \%$ of all tumors affecting women. Its incidence is quite variable worldwide. In North America, its incidence has been calculated to be 99.4 cases per 100,000 women. In regions such as Eastern Europe, South America, the Southern African region and Western Asia, the reported incidence is moderate, however, it is increasing ${ }^{(\mathbf{1})}$. Such a fact is followed by a decrease in mortality, which is intimately related to early detection of breast diseases and to the increasing availability of appropriate treatment ${ }^{(2)}$.

In Portugal, the recorded incidence is approximately 4,000 new cases/year ${ }^{(3)}$.

Mammography is a diagnostic technique aimed at producing detailed images from the internal structures of the breast so as to allow for early diagnosis of breast diseases. The mammographic study comprises the acquisition of two basic views, namely, craniocaudal and mediolateral oblique views. Supplementary views may be acquired whenever the presence of a suspected lesion is detected ${ }^{(4)}$.

In the diagnosis of breast lesions, Bmode ultrasonography (US) has demonstrated to be quite relevant as a complement with other diagnostic modalities. Whenever possible, the sonographic study should always be preceded by a complete mammographic study ${ }^{(5)}$. It is a screening method for younger women with dense breasts at mammography (BI-RADS 3 and 4) ${ }^{(6)}$. The acquisition technique varies among patients, indications, location and type of lesion. Sonographic findings should be documented in two orthogonal planes (longitudinal and cross-sectional) to allow the visualization of all their characteristics.

Currently, sonoelastography has shown to be a promising technique in the followup of suspicious breast lesions in elderly patients, and in the intervals of the mammographic follow-up, thus allowing for guidance in diagnosis and prognosis. At younger ages, such a technique allows the addition of information to the diagnosis of solid lesions, avoiding unnecessary biopsies. It is complementary with B-mode US in the diagnosis of breast diseases. Its main advantages include absence of ionizing radiations, providing more specific data on the possible lesion, besides not requiring a significant increase in time for the investigation of suspected lesions ${ }^{(7)}$. Such a method allows for quantifying the tissues elasticity degree by means of pressure exerted on them ${ }^{(6,8)}$. The lesions are quantified according to a color scale. A transducer that superimposes the color data on the B-mode US images is utilized ${ }^{(9)}$. The color scale ranges from red to blue, and is associated with the benignity/malignancy degree, with the absence of deformation being characterized by the blue color associated to the malignancy degree ${ }^{(6,10)}$.

Breast biopsy is defined as an invasive procedure aimed at confirming the breast lesion detection. Such a procedure relies on the collection of breast tissue specimens which are then histologically analyzed. There are several types of biopsies, which are utilized according to lesion type, size and depth in relation to the skin surface. The post-procedural follow-up depends upon the type of histological finding ${ }^{(\mathbf{1 1})}$.

Thus, the present study is aimed at determining the capability of mammography, B-mode US and sonoelastography to differentiate benign from malignant breast lesions relying on histological results as the gold-standard technique.

The present study reveals itself as an opportune investigation, considering that breast sonoelastography is a relatively recent technique whose diagnostic accuracy is scarcely described in the literature. In case the reliability of the technique in differentiating benign from malignant lesions is proven, the number of unnecessary breast biopsies currently performed could be reduced.

\section{MATERIALS AND METHODS}

The present study population comprised a group of female patients with unilateral or bilateral breast disease who were submitted to imaging studies at the Radiology Services of Hospital do Faro, E.P.E. and at H.P.P. - Hospital Santa Maria de Faro. The sample comprised 12 breast lesions documented by means of mammography, Bmode US and sonoelastography images. The histological results from the biopsies performed on the studied lesions were considered as the gold-standard, so as to increase the specificity of the results. The lack of any of the previously mentioned diagnostic imaging study was defined as an exclusion criterion for the present study.

The mean age of the patients was 54.8 \pm 10.4 years, ranging from 43 to 73 years.

Tables were prepared to simplify the data collection. Such tables include the essential characteristics of the lesions which allowed their classification as benign or malignant with basis on the four diagnostic modalities. By means of observation and analysis of the images from the three imaging methods, as well as the correct filling of the above mentioned tables, it was possible to establish the degree of probability of benignity/malignancy of the studied lesions.

The collected data were exclusively and solely utilized in the present study, and the patients' identity, anonymity and confidentiality were safeguarded.

\section{Mammography}

All the patients were submitted to mammography. The images were acquired in GE Medical System Senographe DMR ${ }^{\circledR}$ and GM Medical System Apollon ${ }^{\circledR}$ mammography apparatuses, with craniocaudal and oblique mediolateral acquisitions, which allowed for the demonstration of the outer and inner quadrants, the upper and lower quadrants, and the inframammary angle, respectively.

The mammographic images were analyzed according to the Breast Imaging Reporting and Data System (BI-RADS ${ }^{\circledR}$ ) from the American College of Radiology. By means of such a system, it is possible to standardize the terms utilized in mammography reports, making it clear, concise and easily understandable ${ }^{(8)}$.

The classification of mammographic findings comprises seven categories directly related to the approach recommendations, as follows ${ }^{(8)}$ :

- Category 0 - Currently utilized in cases whose results depend upon comparison with the previous results or a recall for technical error. Such a category may also be utilized in those cases requiring further investigation by means of US or magnetic resonance imaging (MRI), for diagnosis clarification. 
- Category 1 - Refers to images negative for malignancy, with no evidence of significant focal radiographic alterations.

- Category 2 - Utilized in situations where the mammographic findings are characteristically benign.

- Category 3 - Mammographic findings with high probability of benignity, with positive predictive value (PPV) $\geq 98 \%$.

- Category 4 - Lesions presenting probability of malignancy, but with no typical characteristic of carcinoma.

- Subcategory 4a-Lesions with intermediate malignancy suspicion, with indication for biopsy for histological correlation.

- Subcategory 4b-Amorphous calcifications, nodules with partially circumscribed and partially indistinct contours.

- Subcategory 4c-Lesions under moderate suspicion of malignancy, with expectation of histological result positive for malignancy.

- Category 5 - Lesions whose malignancy probability is high (PPV > 95\%).

- Category 6-Lesions whose malignancy has already been previously histopathologically confirmed and that have not been submitted to any definitive treatment yet.

\section{B-mode US and sonoelastography}

The B-mode US and sonoelastography images were obtained by GE Medical System Logic $9^{\circledR}$ and Siemens Acuson Antares ${ }^{\circledR}$ US apparatuses, with the utilization of a high-frequency linear transducer. The frequencies ranged between 7.5 and $14 \mathrm{MHz}$, depending upon the depth of the lesion and breast thickness. The lesions under study were documented in two orthogonal planes (longitudinal and cross-sectional).

Once the elastography mode is selected, the scale of colors is superimposed over the B-mode image ${ }^{(\mathbf{9})}$. Both images are simultaneously presented on the equipment screen in real time, with the B-mode being presented on the left side and the sonoelastogram being presented at the right side of the screen.

As regards sonoelastography, measurements were performed before and after uniform tissue compression, so as to evaluate the multi-directional deformation of the suspicious breast tissue.
The evaluation of the B-mode US images, similarly to mammography, is performed according to the BI-RADS classification. On the other hand, sonoelastographic images, namely the elastic tissue properties, are quantitatively analyzed according to the Ueno elasticity five-score system (Figure 1) ${ }^{(\mathbf{8 , 1 2 - 1 5})}$, as follows:

- Level 1 - Uniformly elastic lesion, green colored. A variation of this type is the diagnostic image of a cyst $(1 *)$, where three layers are presented (blue, green and red).

- Level 2 - Fundamentally elastic lesion, with some zones of elasticity absence, characterized by a green and blue mosaic pattern.

- Level 3 - Peripheral elasticity and absence of elasticity in the central region of the lesion, with green color at the peripheral zone and blue color within the lesion.

- Level 4-Absence of elasticity in the entire lesion, which is visualized entirely in the blue color.

- Level 5 -Absence of elasticity not only in the entire lesion but also in surrounding tissues, with a blue region more extensive than the lesion itself being visualized.

The levels attributed at sonoelastography may be compared with the BIRADS classification. Levels 1 and 2 at sonoelastography correspond to BI-RADS category 2 . The remaining levels at sonoelastography present a one-to-one correspondence with the BI-RADS classification $^{(\mathbf{9})}$. Thus, level 1 at sonoelastography represents findings negative for malignancy, level 2, benign findings, level 3 , probably benign findings, level 4 demonstrates findings suspicious for malignancy, and level 5 represents findings that are highly suspicious for malignancy ${ }^{(\mathbf{1 6})}$. Therefore, one can affirm that the elasticity level of lesion in intimately correlated with the BI-RADS classification, since low elasticity levels correspond to high BI-RADS categories. The contrary is also true ${ }^{(17)}$.

\section{Histology}

The histological results were available for all patients. Percutaneous US-guided core biopsies with automated biopsy device were performed in nine patients $(75 \%)$ and

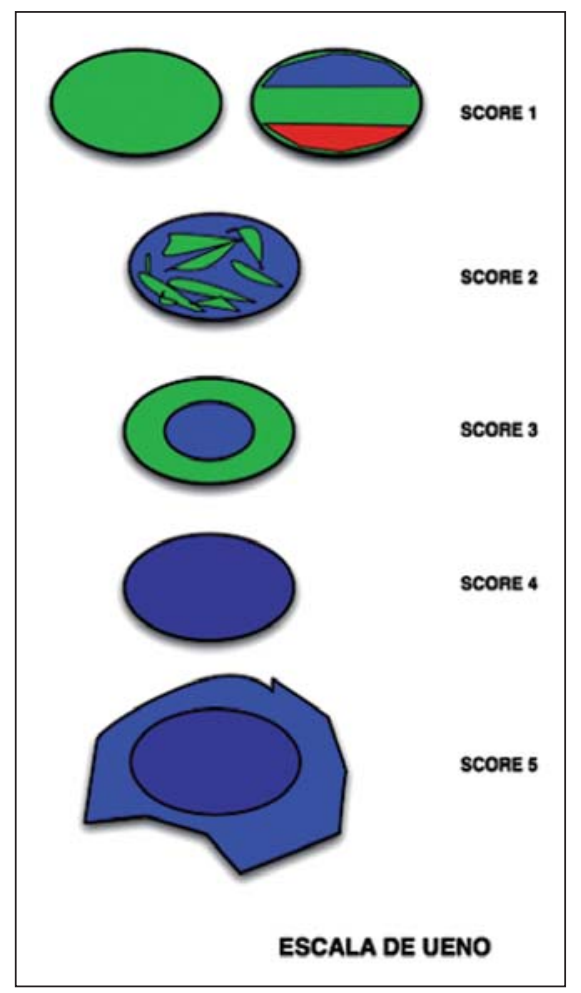

Figure 1. Ueno score system, where elasticity levels are schematically demonstrated ${ }^{(\mathbf{1 3})}$.

stereotactic biopsies were performed in three patients (25\%). The specimens were collected and histologically analyzed in a laboratory.

\section{Statistical analysis}

The obtained results were analyzed with the softwares Microsoft Excel 2010 ${ }^{\circledR}$ and Statistical Package for the Social Sciences (SPSS) V 20.0 ${ }^{\circledR}$.

The Microsoft Excel $2010^{\circledR}$ software was utilized for the calculation of sensitivities, specificities, PPVs and negative predictive values (NPVs) for the three imaging methods.

The SPSS V 20.0 ${ }^{\circledR}$ was utilized to calculate central trend measurements (means) and dispersion measures (standard deviations). The receiver operating characteristic (ROC) curve was also obtained for all the techniques under study. In such a curve, the sensitivity values are represented on the ordinate axis, while on the abscissa axis the 1 - specificity values are represented for all defined cutoff points. The knowledge of the area under the curve allows for the quantification of the accuracy of the diagnostic tests. The $t$-test was also calculated for the 
difference of the mean values, considering an alpha of 0.05 .

\section{RESULTS}

Twelve breast lesions were identified in female patients by means of mammography, b-mode US and sonoelastography (Figures 2 and 3). The histological result was obtained for all patients, with identification of six benign and six malignant lesions measuring, on average, $15.1 \pm 10.6$ $\mathrm{mm}$ and $13.8 \pm 3.8 \mathrm{~mm}$, respectively.

In order to quantify the lesions detected by the imaging methods under study, the frequencies were calculated according to their classification. Mammography identified three lesions classified as BI-RADS 3; five lesions as BI-RADS 4b; and four lesions as BI-RADS 4c, with a mean value of $5.8 \pm 1.2$. B-mode US detected four lesions classified as BI-RADS 3; one lesion classified as BI-RADS 4a; two as BI-RADS $4 \mathrm{~b}$; and 5 as BI-RADS 4c, with a mean values of $5.7 \pm 1.4$. Sonoelastography on its turn, detected 7 lesions quantified as level 2 ; one lesion as level 3; and four lesions as level 4 . Thus the mean value was $2.8 \pm 1$.

With the objective of identifying the number of benign and malignant lesions correctly diagnosed by the imaging methods, with basis on the histological results, the frequencies were calculated. Mammography correctly identified nine of the 12 lesions, three of them classified as BIRADS 3, three as BI-RADS 4b, and three as BI-RADS 4c. B-Mode US correctly identified seven of the 12 lesions (four classified as BI-RADS 3, one as BI-RADS 4b, and one classified as BI-RADS 4c). Finally, sonoelastography correctly identified 10 of the 12 lesions, five of them level 2, one level 3, and four lesions level 4.

Thus, in order to better understand the diagnostic accuracy of the imaging methods under study, their respective sensitivities, specificities, PPVs and NPVs were calculated (Table 1).

In order to quantify the performance of the imaging methods under study, a ROC curve was built, representing the sensitivity values on the ordinate axis and the values of 1-specificity on the abscissa axis (Figure 4).

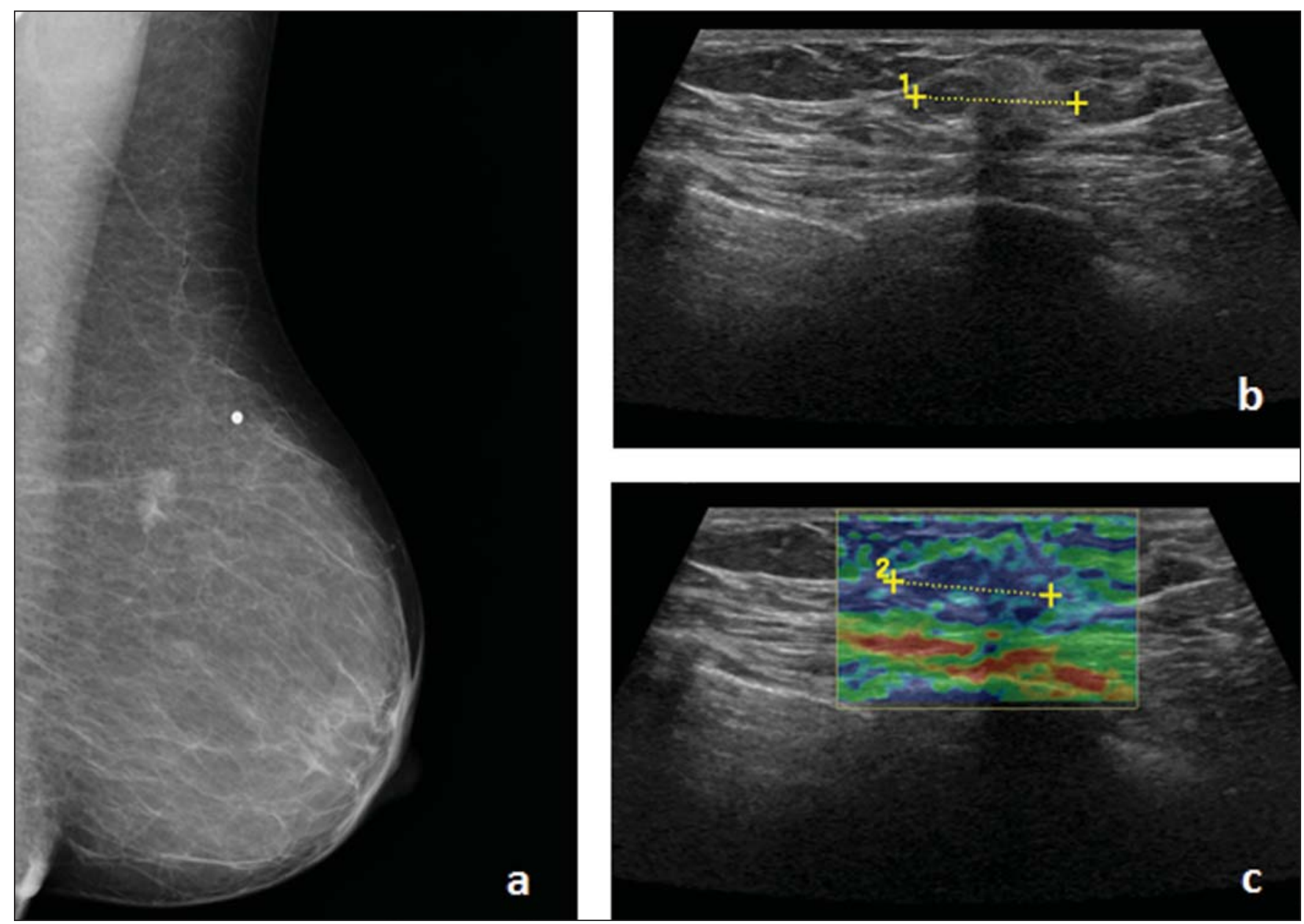

Figure 2. Female, 55-year-old patient with no previous history of breast cancer. Asymmetrical density was detected on her left breast in the year of 2011 , and the lesion increased in size recently. The patient underwent screening mammography where the previously mentioned breast tissue alteration was detected. The patient was referred to Hospital do Faro, where a supplementary investigation was undertaken. A new left oblique mediolateral mammographic view was acquired (a), confirming the presence of an hyperdense, irregular nodule with spiculated margins on the upper outer quadrant, classified as BI-RADS 4c. The US study (b) demonstrates an irregular hypodense area with ill-defined contours, causing an acoustic shadow cone, classified as BI-RADS 4c. Sonoelastography (c) identified a lesion with absence of elasticity, totally blue shaded, corresponding to level 4 in the Ueno scale. Histopathological analysis revealed the presence of an invasive ductal carcinoma. 


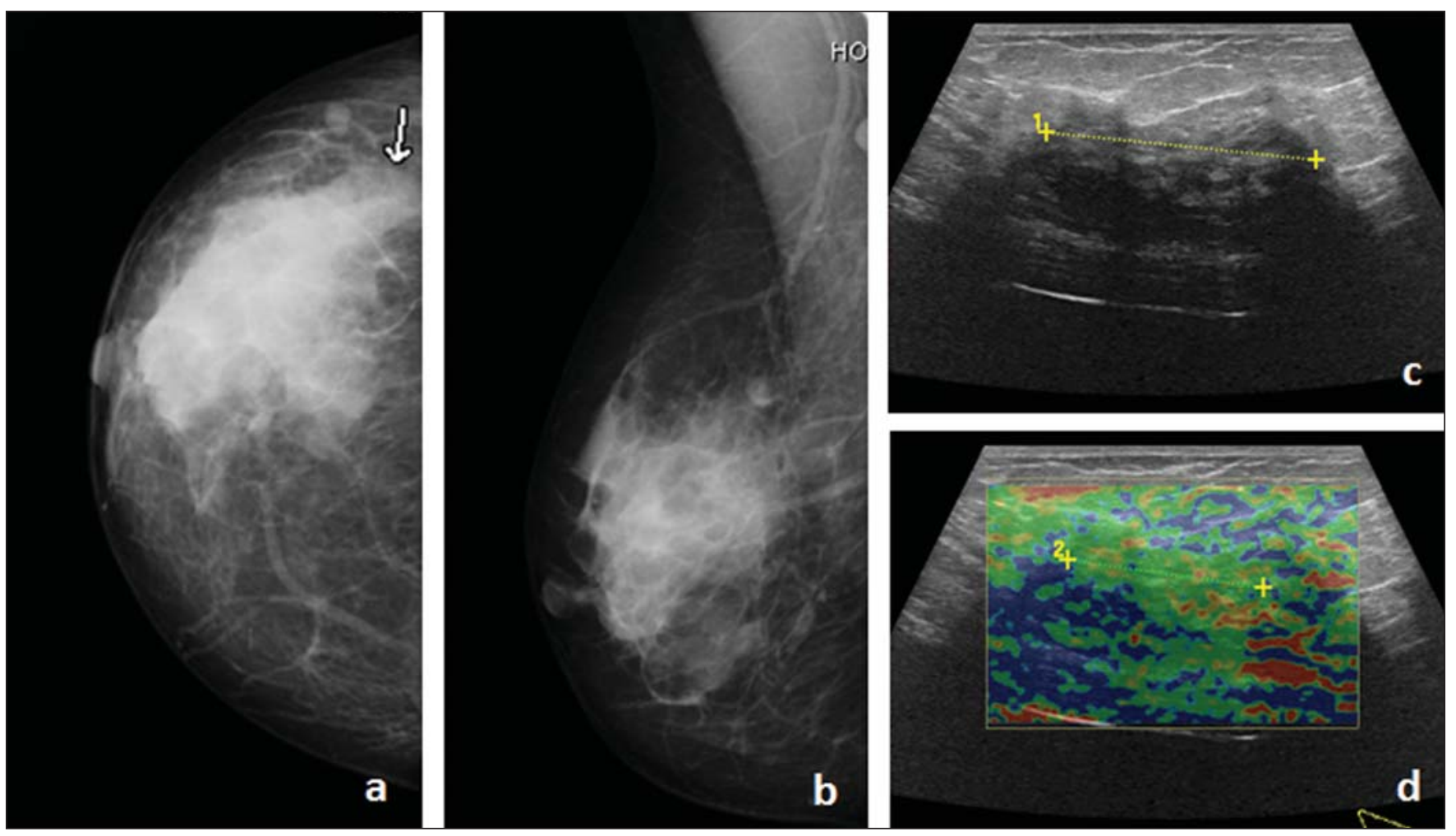

Figure 3. Female 56-year-old patient with a recent history of mastitis in the right upper outer quadrant. Mammography with craniocaudal (a) and oblique mediolateral (b) views revealing an irregular hyperdense region with partially obscured contours, classified as BI-RADS 4b. Sonographic image (c) revealed an ovoid hypodense area with partially obscured margins, causing a acoustic shadow cone, classified as BI-RADS 3. Sonoelastography (d) demonstrated a fundamentally elastic lesion, with some elasticity absence zones, classified as level 2 according the Ueno score system. Histopathological analysis demonstrated the presence of fibroadipose tissue.

Table 1 Sensitivity, specificity, PPV and NPV for the imaging methods under study.

\begin{tabular}{lcccc}
\hline & Sensitivity & Specificity & PPV & NPV \\
\hline Mammography & $100 \%$ & $50 \%$ & $67 \%$ & $100 \%$ \\
B-mode US & $100 \%$ & $71 \%$ & $71 \%$ & $100 \%$ \\
Sonoelastography & $67 \%$ & $83 \%$ & $80 \%$ & $71 \%$ \\
\hline
\end{tabular}

According to Figure 4, the area under the mammography ROC curve was calculated as being 0.792 . B-mode US presented an area of 0.847 under the ROC curve, while sonoelastography presented an area of 0.806 under the ROC curve.

Also, the mean values and respective standard deviations of the Ueno classifications for both benign and malignant lesions were calculated for sonoelastography. Mean values of $2.17 \pm 0.408$ for benign lesions, and $3.33 \pm 1.033$ for malignant lesions were observed. In order to determine if the mean value of the Ueno classification for malignant lesions is significantly higher than the mean Ueno classification for benign lesions, the $t$-test was applied for the difference between mean values, and a $p<0.05$ value was obtained, thus a higher and statistically significant mean value was found for the Ueno classification of malignant lesions.

\section{DISCUSSION}

Considering that an incorrect diagnosis of breast diseases is many times directly related to a failure in perception of the lesion by the investigator, it becomes essential to evaluate the diagnostic capability of the imaging methods for detecting truepositive results (sensitivity) and true-negative results (specificity).

With the progress in medical technologies, it is already possible to utilize sonoelastography in routine diagnoses. Such method presents some advantages, namely, the data obtained is immediately evaluated and superimposed over the B-mode US images, and it does not require more time than conventional B-mode US.

Previous studies demonstrated low sensitivity and high specificity of sonoelastography as compared with B-mode $\mathrm{US}^{(\mathbf{9}}$ ${ }^{14,18)}$. As regards mammography, data on the calculation of sensitivity and specificity in comparison with other imaging methods are still scarce in the literature.

Based on the above mentioned data and according to the present results, one observes that sonoelastography presents sensitivity and specificity to differentiate breast lesions, and also that the three imaging methods under study do not present the same sensitivity and specificity for the same lesions.

The present study is in agreement with the results reported by Thomas et al. ${ }^{\left({ }^{9} \text {, }\right.}$, since B-mode US obtained higher sensitivity $(100 \%$ in the present study and $94 \%$ as reported by Thomas et al. ${ }^{(9)}$ ) and higher 


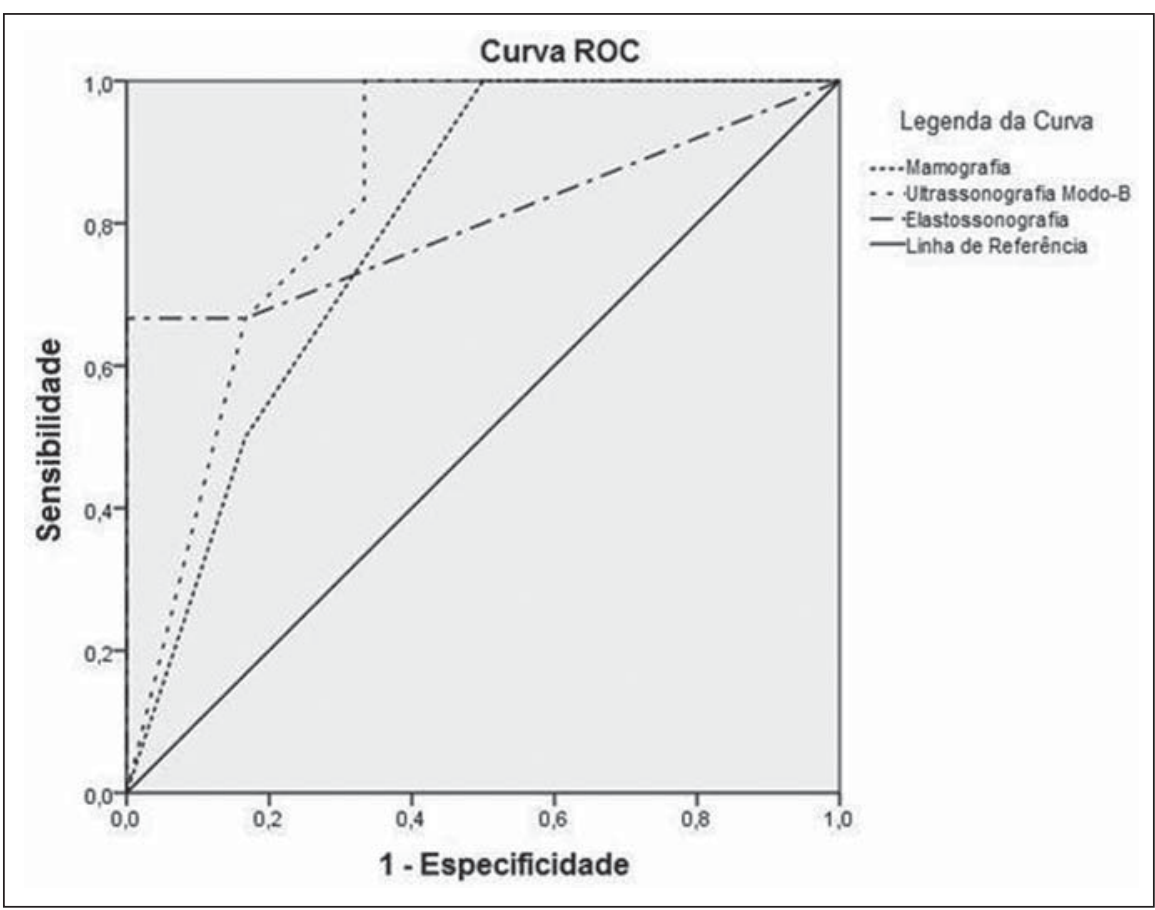

Figure 4. ROC curves representing the sensitivity and specificity values for mammography, B-mode US and sonoelastrography.

NPV $(100 \%$ in the present study and $95 \%$ reported by Thomas et al. $\left.{ }^{(9)}\right)$, while sonoelastography showed lower specificity (83\% in the present study and $87 \%$ reported by Thomas et al. $\left.{ }^{(9)}\right)$. As regards PPV, the study developed by Thomas et al. ${ }^{(9)}$ is in disagreement with the present study, since according to those authors, mammography obtained the highest value $(89 \%)$, while in the present study sonoelastography presented the highest value (80\%). The study developed by Lee et al. ${ }^{(14)}$ is in agreement with the present study, since B-mode US obtained the highest sensitivity value $(95.8 \%)$ and sonoelastography obtained the highest specificity value (45.7\%), and PPV, $23.7 \%$. Only the NPV is different from the present study results, with a higher value being obtained by sonoelastography (97.6\%), as compared with B-mode US result of $100 \%$ obtained in the present study ${ }^{(\mathbf{1 4})}$. The study developed by Mansour et al. ${ }^{(16)}$ is completely in disagreement with the present study, since the results obtained by those authors are contradictory, namely the higher specificity (86.2\%) and higher PPV (81.4\%) were obtained with B-mode US and the higher sensitivity $(92.3 \%)$ and higher NPV (93.4\%) were obtained with sonoelastography.
Thus, it is possible to conclude that the association of the various techniques allows for the improvement of the accuracy in breast lesions diagnosis, since all the imaging methods contribute to the diagnosis. Such association also allows for the reduction of the number of biopsies currently performed.

The mean values of the Ueno classifications for benign and malignant lesions at sonoelastography were calculated, and the $t$-test was utilized to calculate the difference between mean values. The results from present study are in agreement with those reported by Lee et al. ${ }^{(\mathbf{1 4})}$, demonstrating lower mean values $(1.72 \pm 0.78$ for benign lesions, and $3.02 \pm 1.33$ for malignant lesions as compared with the mean values of $2.17 \pm 0.408$ for benign lesions and $3.33 \pm$ 1.033 for malignant lesions in the present study). After the $t$-test, a $p$ value lower than alpha $(p<0.001$ as compared with the $p<$ 0.05 obtained in the present study), also confirming a statistically significant difference between the mean values for malignant and benign lesions.

The ROC curve represents a powerful tool for quantifying the performance of imaging methods. One verified that Bmode US was the method with the largest area under the ROC curve $(0.847)$, followed by sonoelastography (0.806) and mammography (0.792). According to the classification attributed to the areas under the ROC curve, mammography presented a reasonable performance, while both $\mathrm{B}$ mode US and sonoelastography performances were classified as good. It is possible to observe that the values obtained with B-mode US and sonoelastography are quite similar, allowing the assertion that based on such analysis, both methods present a similar diagnostic performance. The results from the present study are different from those reported by Lee et al. ${ }^{(14)}$, with the area under the ROC curve for Bmode US (0.616) lower than that from sonoelastography (0.784), with a weak and reasonable performance, respectively for the two methods. The results reported by Schaefer et al. ${ }^{(\mathbf{1 2})}$ are also different from the results from the present study, with an area under the ROC curve for B-mode US (0.820) lower than that for sonoelastography (0.884), with both methods presenting a good performance.

\section{CONCLUSION}

The present study allows for the conclusion that sonoelastography presents a good diagnostic sensitivity and high diagnostic specificity in the differentiation between benign and malignant lesions, thus allowing for a reduction in the current number of breast biopsies. Although the imaging methods described in the present study do not present the same sensitivity and specificity for the same lesions, their combination may clearly improve the accuracy of the diagnosis of breast lesions.

The main limitation of the present study was the reduced sample size, conditioned by the reduced number of breast biopsies performed over the data collection period.

As a recommendation for future studies, the authors suggest that prospective studies are undertaken about the theme in question with a larger sample and in different clinical centers, in order to determine whether a quantitative analysis of the images may be useful to overcome some shortcomings of the method. The authors also wish to propose that breast MRI be included in the studies, so as the compari- 
son can cover the whole range of imaging methods.

\section{REFERENCES}

1. World Health Organization. Breast cancer: prevention and control. World Health Organization. [Online] 2012. [cited 2012 Sept 5]. Available from: http://www.who.int/cancer/detection/ breastcancer/en/index 1.html.

2. Oliveira FGTF, Fonseca LMB, Koch HA. Responsabilidade civil do radiologista no diagnóstico do câncer de mama através do exame de mamografia. Radiol Bras. 2011;44:183-7.

3. Ministério da Saúde. Guia de apoio à mulher com cancro da mama. Direcção Geral de Saúde. [Online] 2011. [cited 2012 Sept 5]. Available from: http://www.dgs.pt/.

4. Kopans DB. Imagem da mama. $2^{a}$ ed. Rio de Janeiro: Medsi; 2000.

5. Dronkers DJ, Hendriks JHCL, Holland R, et al. The practice of mammography. New York: Thieme; 2002.
6. Fleury EFC, Rinaldi JF, Piato S, et al. Apresentação das lesões mamárias císticas à ultra-sonografia utilizando a elastografia. Radiol Bras. 2008, 41:167-72.

7. Stavros AT, Rapp CL, Parker SH. Breast ultrasound. Philadelphia: Lippincott Williams \& Wilkins; 2004.

8. Camps J, Sentis C. Elastosonografia mamaria. Rev Chil Radiol. 2008;14:122-7.

9. Thomas A, Kümmel S, Fritzsche F, et al. Realtime sonoelastography performed in addition to B-mode ultrasound and mammography: improved differentiation of breast lesions? Acad Radiol. 2006;13:1496-504.

10. Kemp C, Baracat FF, Rostagno R. Lesões não palpáveis da mama: diagnóstico e tratamento. Rio de Janeiro: Revinter; 2003.

11. Aguillar V, Bauab S, Maranhão N. Mama - diagnóstico por imagem. Rio de Janeiro: Revinter; 2009.

12. Schaefer FK, Heer I, Schaefer PJ, et al. Breast ultrasound elastography - results of 193 breast lesions in a prospective study with histopathologic correlation. Eur J Radiol. 2011;77: 450-6.

13. Tan S, Teh HS, Mancer JF, et al. Improving B mode ultrasound evaluation of breast lesions with real-time ultrasound elastography - a clinical approach. Breast. 2008;17:252-7.

14. Lee JH, Kim SH, Kang BJ, et al. Role and clinical usefulness of elastography in small breast masses. Acad Radiol. 2011;18:74-80.

15. Itoh A, Ueno E, Tohno E, et al. Breast disease: clinical application of US elastography for diagnosis. Radiology. 2006;239:341-50.

16. Mansour SM, Omar OS. Elastography ultrasound and questionable breast lesions: does it count? Eur J Radiol. 2012;81:3234-44.

17. Ueno E, Iboraki P. Clinical application of US elastography in the diagnosis of breast disease. European Congress of Radiology. 5-9 March 2004; Vienna, Austria.

18. Zhu QL, Jiang YX, Liu JB, et al. Real-time ultrasound elastography: its potential role in assessment of breast lesions. Ultrasound Med Biol. 2008;34:1232-8. 